\title{
Blocos de concretos fabricados com incorporação de resíduos sólidos: Uma revisão sistemática
}

\section{Concrete blocks manufactured with solid waste: A systematic review}

\author{
${ }^{1}$ Isabela Pinheiro Oliveira, ${ }^{2}$ Ivan Julio Apolonio Callejas, ${ }^{3}$ Luciane Cleonice Durante \\ ${ }^{1}$ Aluna de Iniciação Científica - Graduanda em Engenharia Civil pela Universidade Federal de Mato Grosso \\ (isabelapinheiro13@gmail.com) \\ ${ }^{2}$ Docente do Departamento de Arquitetura e Urbanismo - Universidade Federal de Mato Grosso \\ (ivancallejas@ufmt.br) \\ ${ }^{3}$ Docente do Departamento de Arquitetura e Urbanismo - Universidade Federal de Mato Grosso
}

(luciane.durante@hotmail.com)

\begin{abstract}
RESUMO: As atividades da construção civil são grandes geradoras de poluição ambiental e, a partir disso, fazse pertinente a busca por métodos e materiais alternativos, que possam agregar mais sustentabilidade ao setor. Em paralelo, tem-se a problemática da geração e descarte dos resíduos sólidos urbanos, para a qual também se fazem necessárias soluções de reutilização. Aliando essas questões, diversos estudos têm abordado a incorporação de resíduos na produção de blocos de concreto de alvenaria estrutural ou de vedação. Neste trabalho, realizou-se uma revisão sistemática com o objetivo de analisar as propriedades físico mecânicas de blocos de concreto reciclados, à luz das normativas brasileiras. Os objetivos específicos são: a) relacionar a resistência mecânica dos blocos com a absorção de água e com a relação água/cimento de seus traços, avaliando como esses fatores interferem entre si, e b) classificar estatisticamente o comportamento físico mecânico dos blocos de concreto reciclados. Evidenciou-se que o coeficiente de determinação foi de 0,1955 (moderado) e 0,0031 (muito baixo) entre a resistência à compressão e a absorção de água e a relação água/cimento, respectivamente. A análise de agrupamento aplicada às propriedades dos blocos determinou seis grupos com similaridade, onde se observa a tendência dos blocos com maiores resistências possuírem menor absorção de água, e vice versa. Concluiu-se que a incorporação de resíduos permite o enquadramento da maioria dos blocos analisados às normas, devendo-se fazer uma análise cuidadosa das propriedades e características dos resíduos utilizados, com vistas a verificar como estes podem afetar suas propriedades físicas e mecânicas.
\end{abstract}

Palavras Chave: Reciclagem. Agregado reciclado. Resistência à compressão. Absorção de água.

\begin{abstract}
Civil Engineering activities are a great generator of environmental pollution. Considering that, it is necessary to search for alternative methods and materials, which can add more sustainability to the sector. In parallel, there is the problem of the generation and disposal of solid urban waste, for which reuse solutions are also necessary. Combining these issues, several studies have addressed the incorporation of waste in the production of structural masonry or sealing concrete blocks. In this work, a systematic review was carried out to analyze the physical and mechanical properties of recycled concrete blocks, considering the Brazilian regulations. Specific objectives are: a) to relate the mechanical strength of the blocks to the water absorption and the water/cement ratio of their mixtures, evaluating how these factors that interfere with each other, and b) to statistically classify the physical and mechanical behavior of the recycled concrete blocks. It was evident that coefficient of determination was 0.1955 (moderate) and 0.0031 (very low) between the compressive strength and water absorption and the water/cement ratio, respectively. The grouping analysis applied to the properties of the blocks, determined six groups with similarity, where the tendency of the blocks with greater resistance is observed to have less water absorption, and vice versa. It was concluded that the incorporation of waste allows attending the blocks specification in the Brazilian standards, with a careful analysis of the properties and characteristics of the waste used, to verify how they can affect their physical and mechanical properties.
\end{abstract}

Keywords: Recycling. Recycled aggregate. Compressive strength. Water absorption.

\section{INTRODUÇÃO}

A construção civil é um importante setor da economia global. Entretanto, esse setor também é um grande gerador de impacto ambiental, devido ao elevado consumo de recursos naturais em seus insumos, a alteração de áreas vegetadas e geração de resíduos em seus empreendimentos, entre outros fatores. A partir disso, torna-se cada vez mais pertinente a 
busca por alternativas de métodos e materiais mais sustentáveis e que apresentem viabilidade de serem incorporados pela construção civil. Uma das alternativas que se apresenta é a incorporação de resíduos sólidos nos materiais construtivos, pois apesar de descartados, muitos desses rejeitos possuem elevado potencial de reciclagem.

Segundo a NBR 10004 (ABNT, 2004), os resíduos podem ser de origem industrial, doméstica, hospitalar, comercial, agrícola, de serviços e de varrição. Já os resíduos sólidos são qualquer material descartado nos estados sólido ou semissólido, resultante de atividades humanas em sociedade. Entende-se por reciclagem, o processo de transformação de resíduos sólidos que envolve a alteração de suas propriedades físicas, físico-químicas ou biológicas, com vistas à transformação em insumos ou novos produtos (BRASIL, 2010). Com base nesses conceitos, doravante, os blocos de concreto com resíduos incorporados em sua produção denominam-se blocos de concreto reciclados.

Os blocos de concreto reciclados para alvenaria se apresentam como uma alternativa para os blocos produzidos integralmente com matérias primas virgens. De acordo com a NBR 6136 (ABNT, 2016), os blocos vazados de concreto simples são componentes para a execução de alvenaria, com ou sem função estrutural, vazado nas faces superior e inferior, cuja área líquida é igual ou inferior a 75\% da área bruta. Segundo Salvador Filho (2007), os materiais comumente utilizados na confecção dos blocos de concreto são o cimento Portland, água e agregados graúdos e miúdos, além de aditivos, de acordo com a necessidade. Terra (2018) afirma que, as propriedades dos agregados têm grande importância na fabricação dos blocos, por interferirem na resistência e compactação do concreto, na aderência com a pasta de cimento, bem como na homogeneidade da mistura. Por meio da NBR 6136 (ABNT, 2016), os blocos podem ser classificados de acordo com sua função, a partir de suas capacidades de resistência, absorção e retração, como blocos classe A e B (com função estrutural) e classe C (com ou sem função estrutural).

Esse estudo se propôs a identificar, por meio de uma revisão sistemática, estudos científicos já desenvolvidos sobre blocos de concreto reciclados a partir de resíduos de origens variadas, tais como Resíduos de Construção e Demolição (RCD), Politereftalato de Etileno (PET), areia de descarte de fundição, borracha de pneu, dentre outros. A partir do corpus obtido na revisão sistemática, tem-se por objetivo geral analisar as propriedades físicomecânicas de blocos de concreto reciclados, à luz das normativas brasileiras. Especificamente, objetivos são: a) relacionar a resistência mecânica dos blocos com a absorção de água e com a relação água/cimento de seus traços, avaliando como esses fatores interferem entre si e b) classificar estatisticamente o comportamento físico mecânico dos blocos de concreto reciclados.

\section{MATERIAIS E MÉTODOS}

Segundo Dresch, Lacerda e Antunes Júnior (2014), pode-se definir revisão sistemática da literatura como um estudo secundário, utilizado para mapear, avaliar criticamente, consolidar ou agregar resultados relevantes de estudos primários acerca de uma questão ou tópico de pesquisa específico, de forma a resultar em um relatório coerente ou em uma síntese. A questão proposta para a presente revisão sistemática é: "Os blocos de concreto reciclados para alvenaria atendem aos parâmetros de resistência à compressão e absorção de água estabelecidos pela NBR 6136 (ABNT 2016)?”.

As bases de dados selecionadas para a pesquisa foram: Science Direct, Google Acadêmico, CAPES, Scielo e repositórios da USP e UNB, nas quais buscaram-se estudos científicos do tipo monografias, artigos, dissertações e teses.

As buscas foram realizadas em duas etapas. Na primeira etapa, definiram-se termos de busca principais pertinentes ao tema pesquisado, sendo eles: "Blocos de concreto", "Blocos 
de vedação", "Blocos estruturais", "Blocos de concreto reciclados", "Agregados reciclados", "Resíduos sólidos", "Resíduos de construção e demolição", "RCC", "RCD", "Resíduos orgânicos", "Resíduos vegetais", "Resíduos poliméricos" "Resíduos plásticos", "Resíduos industriais", "Resistência mecânica" e "Resistência à compressão".

$\mathrm{Na}$ segunda etapa, visando abranger o maior número possível de estudos pertinentes ao tema, foram realizadas buscas utilizando combinações dos termos anteriores, de forma a se localizar estudos contendo os termos no título ou no desenvolvimento do trabalho. Foram excluídos os termos como "Blocos de pavimentação", "Pavimentação" e "Paver". A busca se restringiu aos estudos publicados nos últimos oito anos.

Segundo a metodologia proposta por Dresch, Lacerda e Antunes Júnior (2014), após realizar a busca sistemática de trabalhos, deve-se proceder uma pré-avaliação dos estudos primários encontrados, baseando-se em três dimensões: a qualidade da execução do estudo, sua adequação à questão da revisão e sua adequação ao foco da revisão. Para cada uma dessas dimensões, deve-se atribuir a classificação da qualidade, conforme os critérios indicados na Tabela 1. A classificação final de cada estudo é obtida ponderando-se a classificação nas três dimensões, conforme critérios da Tabela 2. Foram considerados relevantes para essa revisão sistemática, os trabalhos que apresentaram avaliação de qualidade "Alta", após o processo de ponderação.

Tabela 1 - Critérios para avaliação das dimensões de qualidade de estudos primários

\begin{tabular}{|c|c|c|c|}
\hline & Qualidade da execução do estudo & $\begin{array}{c}\text { Adequação à questão } \\
\text { da revisão }\end{array}$ & $\begin{array}{c}\text { Adequação ao foco da } \\
\text { revisão }\end{array}$ \\
\hline 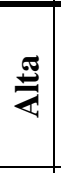 & $\begin{array}{r}\text { O método proposto atende aos p } \\
\text { o tema em estudo, o estudo segu } \\
\text { método proposto e os resultados } \\
\text { e dados. }\end{array}$ & $\begin{array}{l}\text { O estudo aborda } \\
\text { exatamente o assunto } \\
\text { alvo da revisão } \\
\text { sistemática. }\end{array}$ & $\begin{array}{l}\text { O estudo foi realizado } \\
\text { em um contexto } \\
\text { idêntico ao definido } \\
\text { para a revisão. }\end{array}$ \\
\hline 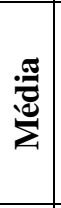 & $\begin{array}{l}\text { O método proposto possui lacunas em relação aos } \\
\text { padrões exigidos para o tema em estudo ou o estudo } \\
\text { não demonstra ter seguido o método proposto na sua } \\
\text { totalidade ou os resultados não se apoiam } \\
\text { integralmente em fatos e dados. }\end{array}$ & $\begin{array}{r}\mathrm{O} \text { estudo ab } \\
\text { parcialmente o } \\
\text { alvo da rev } \\
\text { sistemátic }\end{array}$ & $\begin{array}{r}\mathrm{O} \text { estudo foi } \\
\text { em um cc } \\
\text { semelhante a } \\
\text { para a re }\end{array}$ \\
\hline 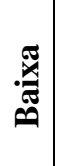 & $\begin{array}{l}\text { O método proposto não est } \\
\text { padrões exigidos para o tema } \\
\text { não demonstra ter seguido o } \mathrm{n} \\
\text { resultados não se apoiam }\end{array}$ & $\begin{array}{l}\text { O estudo apenas } \\
\text { tangencia o assunto alvo } \\
\text { da revisão sistemática. }\end{array}$ & $\begin{array}{c}\text { O estudo foi realizado } \\
\text { em um contexto diverso } \\
\text { do definido para a } \\
\text { revisão. }\end{array}$ \\
\hline
\end{tabular}

Fonte: Dresch, Lacerda e Antunes Júnior (Adaptado) (2014).

Tabela 2 - Ponderação das dimensões

\begin{tabular}{c|c|c|c}
\hline \multicolumn{2}{c|}{ Avaliação das dimensões } & Avaliação do Estudo \\
\hline Alta & Alta & Alta & Alta \\
\hline Alta & Alta & Média & Média \\
\hline Alta & Média & Média & Média \\
\hline Média & Média & Média & Baixa \\
\hline Alta & Alta & Baixa & Baixa \\
\hline Alta & Média & Baixa & Baixa \\
\hline Média & Média & Baixa & Baixa \\
\hline Média & Baixa & Baixa &
\end{tabular}

Fonte: Dresch, Lacerda e Antunes Júnior (Adaptado) (2014). 
Os estudos selecionados foram classificados de acordo com o tipo de resíduo incorporado ao traço do bloco de concreto, a saber: resíduos poliméricos, resíduos de construção e demolição, resíduos minerais e resíduos orgânicos. Foram coletados, em cada trabalho, dados acerca das seguintes variáveis: resistência à compressão, da absorção da água e da relação água/cimento do traço dos blocos. Esses dados foram tabulados a fim de serem apresentados por meio de gráficos de dispersão, que possibilitaram a análise da correlação entre as variáveis.

Para análise do comportamento dos dados coletados, referentes as propriedades de resistência mecânica e absorção de água dos blocos, aplicou-se a estatística do tipo análise de agrupamento, uma técnica exploratória de análise multivariada que consiste em agrupar indivíduos ou variáveis em grupos homogêneos de acordo com suas similaridades, de forma a organizar os dados em estruturas que façam sentido (CALLEJAS, 2015). Segundo Doni (2004), neste método, os grupos são representados por um diagrama denominado dendograma ou diagrama de árvore, constituído por ramos, que representam os grupos, e pela raiz, que representa o agrupamento de todos os grupos. O dendograma foi produzido utilizando-se o método de soma de erros quadráticos ou variância (Ward) e a distância métrica de Manhattan.

Os dados coletados referentes aos parâmetros de resistência à compressão e de absorção de água, foram avaliados de acordo com a NBR 6136 (ABNT 2016), que determina a resistência mínima de $3 \mathrm{MPa}$ para blocos com ou sem função estrutural (Classe C), bem como absorção de água máxima, para esta classe, de $10 \%$ e $13 \%$, para blocos com agregados normais e leves, respectivamente. A retração dos blocos não foi analisada neste trabalho.

\section{RESULTADOS}

Foram pré-selecionados 53 trabalhos e, após aplicação dos critérios de avaliação de apresentar qualidade "Alta", foram selecionados 40 trabalhos para compor a revisão sistemática (Tabela 3).

Tabela 3 - Avaliação dos trabalhos selecionados

\begin{tabular}{|c|c|c|c|}
\hline Referência & Tipo & Referência & Tipo \\
\hline BORGES (2012) & TCC & PADILHA (2017) & Dissertação \\
\hline MATTAR e VIANA (2012) & Artigo & CALDAS (2018) & Artigo \\
\hline LINTZ et al. (2012) & Artigo & DANIEL, PIVA e ANTUNES (2018) & TCC \\
\hline BRAVO (2014) & Dissertação & FERREIRA et al. (2018) & Artigo \\
\hline LIMA e IWAKIRI (2014) & Artigo & GONÇALVES (2018) & Dissertação \\
\hline MESQUITA et al. (2015) & Artigo & KOBAYASHI (2018) & TCC \\
\hline ALVES (2016) & Dissertação & PRAZERES (2018) & TCC \\
\hline BASTOS, CRUZ e WOELFFEL (2016) & Artigo & TERRA (2018) & Dissertação \\
\hline QUEIROZ e BORJA (2016) & Artigo & TIBURCIO (2018) & TCC \\
\hline SILVA et al. (2016) & Artigo & ARAÚJO et al. (2019) & Artigo \\
\hline SILVA (2016) & Tese & BARRETO et al. (2019) & Artigo \\
\hline $\begin{array}{l}\text { OLIVEIRA, PEREIRA e NOGUEIRA } \\
(2016)\end{array}$ & Artigo & CAMPOS (2019) & Artigo \\
\hline $\begin{array}{l}\text { ALMEIDA, ANACLETO e COSTA } \\
\text { (2017) }\end{array}$ & TCC & $\begin{array}{l}\text { MOZER, LOPES e WOELFFEL } \\
\text { (2019) }\end{array}$ & Artigo \\
\hline COSTA (2017) & TCC & MACHADO (2019) & Artigo \\
\hline GOMES et al. (2017) & Artigo & SILVA et al. (2019) & Artigo \\
\hline LOPES (2017) & Dissertação & SILVA (2019) & TCC \\
\hline MARTINI (2017) & TCC & ANACLETO (2020) & Dissertação \\
\hline MOREIRA et al. (2017) & Artigo & BENITTEZ (2020) & Dissertação \\
\hline NAPOMUCENO, REIS e COSTA (2017) & Artigo & COSTA $(2020)$ & Dissertação \\
\hline NOVAES, FUJIMOTO e PETITTO (2017) & Artigo & GHISLENI e LIMA (2020) & Artigo \\
\hline
\end{tabular}




\subsection{Blocos de concreto com a adição de resíduos poliméricos}

O PET (Politereftalato de etileno) é um polímero termoplástico resistente e muito utilizado como material para embalagens descartáveis. Segundo Silva (2016), destacam-se entre as principais propriedades do PET a sua baixa densidade, transparência, alta resistência mecânica e química e boa barreira para odores e gases.

Através da produção de blocos de concreto com incorporações do agregado de PET em teores variados, os estudos de Silva (2016), Tiburcio (2018) e Barreto et al. (2019) constataram que, a presença deste resíduo no traço provoca, em geral, o aumento da absorção de água nos blocos reciclados, ocasionando maior porosidade e, consequentemente, menor resistência mecânica em comparação com os blocos de referência. Silva (2016) justificou o aumento da porosidade e do percentual de absorção da água devido às características hidrofóbicas do PET, que fazem com que a água presente seja absorvida pela matriz cimentícia, aumentando a quantidade de água necessária para sua hidratação. Esses estudos indicaram uma relação entre o aumento do teor de agregado reciclado e a queda da resistência mecânica, havendo uma redução de resistência em torno de até $60 \%$ nos blocos com maior incorporação de PET em relação aos blocos de referência. De acordo com Silva (2016) e Tiburcio (2018) isso ocorre devido à menor capacidade resistiva dos agregados de polímeros em comparação com os agregados naturais, e a ausência de interação química entre o polímero e a matriz cimentícia do concreto. Os blocos produzidos por Tiburcio (2018), com a incorporação de PET, não obtiveram resistências em conformidade com a norma para blocos de vedação ou estrutural.Já, os blocos de Silva (2016) e Barreto et al. (2019) atenderam aos requisitos, com exceção do bloco com teor de $45 \%$.

Assim como o PET, o EPS (poliestireno expandido) é um polímero muito utilizado, cujo descarte também contribui para a poluição ambiental. Gonçalves (2018) e Moreira et al. (2017) investigaram a utilização desse material em substituição ao agregado graúdo na produção de blocos de concreto. Em sua pesquisa, Gonçalves (2018) constatou um maior índice de vazios e menor massa específica para os agregados de EPS em relação aos agregados naturais. Essa propriedade reflete na capacidade de absorção de água dos blocos, que além de aumentar com o teor de EPS incorporado na mistura, apresenta valor acima do obtido para os blocos de referência. Os blocos de ambos os autores obtiveram comportamento similar em relação à resistência mecânica, obtendo um ligeiro acréscimo de resistência para os blocos produzidos com o menor teor de incorporação. Gonçalves (2018) observou um aumento de $2 \%$ para o bloco com teor de $5 \%$, sendo apenas este a atender os parâmetros normativos de resistência, enquanto Moreira et al. (2017) obteve um aumento de 5\% para o teor de $20 \%$, e todos os blocos em conformidade com a norma.

Por sua vez, Silva et al. (2019), além de adicionar o EPS em substituição ao agregado graúdo, também utilizou garrafas de PET como material de enchimento na confecção dos blocos, obtendo uma elevada redução na capacidade resistiva e aumento na absorção da água de $58,8 \%$ para o EPS e de 3,58\%, para o PET. Isso pode ter ocorrido em decorrência do processo produtivo empregado no estudo, no qual realizou-se a moldagem e compactação dos blocos manualmente. Apesar disso, os blocos reciclados apresentaram resistência acima de 3MPa. Mattar e Viana (2012) utilizaram materiais plásticos irrecuperáveis em substituição ao agregado graúdo nos teores de $5 \%$ e $10 \%$. Apesar de não ter sido produzido um bloco de referência, observou-se que, para ambos os traços, houve um acréscimo da absorção de água e uma redução na resistência com o aumento do teor de plástico, sendo que apenas os blocos com incorporação de $5 \%$ alcançaram o mínimo de $3 \mathrm{MPa}$.

De acordo com Costa (2020), os pneus inservíveis, aqueles que já se encontram no final da vida útil, são grandes responsáveis pela poluição do meio ambiente quando depositados em lugares inadequados e sem controle. Em seu estudo, analisou o uso da borracha de pneu em substituição ao agregado miúdo, constatando uma redução na resistência 
mecânica de $28 \%$ a $62 \%$ com a adição do resíduo, em comparação com o bloco de referência. Para Bravo (2014) que produziu blocos com incorporação de borracha no agregado miúdo e metacaulim no cimento, a maior redução da capacidade resistiva encontrada foi de $81 \%$ para o bloco com maior teor do polímero $(26,8 \%)$. Para ambos os autores, essa redução, também observada no estudo de Oliveira, Pereira e Nogueira (2016), é resultado da má aderência entre a borracha, a matriz cimentícia e os demais componentes do concreto. Além disso, Costa (2020) também afirmou que, a obtenção deste resultado pode ter sido influenciada pela baixa rigidez da borracha de pneu e pelo aumento da porosidade do bloco provocada por esse resíduo. Apesar da redução, Costa (2020) e Bravo (2014) ainda obtiveram resistências em conformidade com a norma, para os menores teores de substituição, enquanto Oliveira, Pereira e Nogueira (2016), que substituiu $10 \%$ da brita por borracha de pneu, também obteve resultados satisfatórios. Nos estudos de Costa (2020) e Bravo (2014) foi constatado o acréscimo da absorção de água com a incorporação de pneu nos blocos, ao contrário do observado por Nepomucemo, Reis e Costa (2017), que produziram blocos com total substituição dos agregados naturais por RCC e borracha, e obtiveram redução de quase $8,71 \%$ na absorção dos blocos reciclados em relação aos blocos convencionais. Os blocos produzidos por Nepomucemo, Reis e Costa (2017), também estiveram em conformidade com os parâmetros normativos.

\subsection{Bloco de concreto com adição de resíduos de construção civil}

Diversos estudos abordaram a reutilização do RCD na forma de agregado reciclado na produção de blocos de concreto, substituindo parcialmente o uso dos agregados naturais. $\mathrm{O}$ estudo de Daniel, Piva e Antunes (2018), verificou uma redução na resistência à compressão e aumento da absorção de água nos blocos com o aumento do acréscimo de RCD na mistura. Neste trabalho, houve uma diminuição de aproximadamente 65 e $57 \%$ da resistência para os dois traços com maiores teores de resíduo. Esse comportamento foi associado à menor massa específica e maior porcentagem de absorção obtida para o agregado de RCD em relação ao agregado natural. Apesar disso, apenas os traços com maiores teores de incorporação não alcançaram a resistência mínima da norma.

Nos estudos de Borges (2012), Lintz et al. (2012), Costa (2017), Lopes (2017) e Araújo et al. (2019) também foram observados esses comportamentos na resistência e absorção da água com a incorporação de RCD. Lopes (2017), que utilizou três traços de referência com diferentes consumos de cimento, obteve reduções na resistência com o aumento do teor de agregado reciclado nas porcentagens de 38 a $55 \%$. Já no trabalho de Gomes et al. (2017) foi observado que, a maior resistência a compressão foi obtida para o bloco com maior incorporação de RCD, o que pode ter ocorrido devido a adoção da mesma quantidade de água para todos os traços, afetando negativamente os blocos com menor teor de resíduo.

Apesar das reduções na capacidade resistente, a maior parte dos blocos produzidos por Borges (2012), Lintz et al. (2012), Costa (2017), Lopes (2017) e Araújo et al. (2019) obtiveram resistências acima do mínimo que a norma estipula para blocos de vedação (3MPa), com alguns apresentando resistência suficiente para serem utilizados como alvenaria estrutural.

Ao contrário dos estudos citados anteriormente, houve trabalhos que constataram maiores resistências para os blocos com RCD do que para os blocos convencionais. (MESQUITA et al., 2015; MOREIRA et al., 2017; NOVAES; FUJIMOTO; PETITTO, 2017; KOBAYASHI, 2018; MACHADO, 2019). Em seu estudo, Kobayashi (2018) que substituiu $90 \%$ do agregado miúdo e $100 \%$ do agregado graúdo, obteve um acréscimo de aproximadamente 7,15\% na resistência, alcançando 7,5 MPa. Machado (2019), que para o teor de $100 \%$ de RCD obteve um aumento de resistência de $61 \%$, atribuiu esse acréscimo ao 
concreto presente na composição do resíduo, que contribuiu para a melhor relação cimento/agregado do traço. Por sua vez, Mesquita et al. (2015) atribuiu os resultados positivos encontrados para as resistências em seu estudo, à redução da relação água/cimento adotada para os blocos com maior incorporação de agregado reciclado.

Novaes, Fujimoto e Petitto (2017) e Moreira et al. (2017) obtiveram maiores valores de resistência para incorporações parciais de RCD. Novaes, Fujimoto e Petitto (2017) obtiveram um aumento de 42,3 e 36\% para os blocos com incorporação de 40 e 60\%, respectivamente. Entretanto, apesar do aumento na resistência, os blocos não atingiram a resistência mínima da norma. Enquanto isso, Moreira et al. (2017) obtiveram acréscimo de 4,8 e $18 \%$ para os teores de 20 e $30 \%$, respectivamente, alcançando resistências acima de $6 \mathrm{MPa}$, além de observarem uma redução da absorção dos blocos reciclados em relação aos blocos de referência.

No estudo de Bastos, Cruz e Woelffel (2016), apesar de não terem sido produzidos blocos sem incorporação de resíduos a fim de servir como referência, os blocos reciclados apresentaram, em geral, resistência satisfatória para serem utilizados como vedação, apesar das elevadas porcentagens de absorção da água. Os blocos produzidos por Bastos, Cruz e Woelffel, (2016), com 100\% da areia natural substituída por RCD, apresentaram resistência de 6,47 MPa e absorção de 16,62\%, que, apesar de ser maior que o limite normativo de $10 \%$, poderiam ter utilidade se empregados como vedação para áreas internas, segundo os autores.

\subsection{Blocos de concreto com a adição de resíduos minerais}

Alguns estudos abordaram a aplicação de areia de descarte de fundição (ADF) na produção de blocos de concreto, sendo esse resíduo utilizado em operações de moldagem e fusão de metais e constituído por areia de sílica, carvão, bentonita e água (MARTINI, 2017). A presença de sílica na composição da ADF torna seu uso viável na construção civil, devido as propriedades pozolânicas que a sílica possui (CAMPOS et al., 2019).

Devido à sua granulometria, em todos os estudos pesquisados, a ADF foi utilizada em substituição ao agregado miúdo na composição do traço, em porcentagens que variaram de 10 a 50\%. Os ensaios de caracterização realizadas com esse resíduo atestaram que, em geral, ele possui menor massa específica que a areia natural, tendo, portanto, maior porosidade (SILVA et al, 2016; MARTINI, 2017; CAMPOS et al., 2019; GHISLENI E LIMA, 2020). Esta propriedade reflete na menor resistência à compressão e maior absorção da água obtida nos blocos de concreto com incorporação deste resíduo, em comparação com os blocos de referência. Nos estudos de Martini (2017) e Campos et al. (2019) obtiveram-se reduções nas resistências entre 5 e 10,87\% para teores de incorporação de 13 a $25 \%$, enquanto para Ghisleni e Lima (2020), foi obtida redução de 52,66\% para o maior teor de ADF incorporado (30\%). Entretanto, apesar das reduções observadas nas resistências, em geral, o resíduo de ADF ainda proporcionou aos blocos reciclados, resistências satisfatórias para seu uso como material estrutural.

Além do resíduo de ADF, diversos autores têm avaliado a incorporação do resíduo proveniente do vidro nos blocos de concreto. O vidro é um material $100 \%$ reciclável, que possui elevados valores de resistência mecânica e é constituído em $70 \%$ por sílica, sendo adequado para a incorporação no concreto devido às suas propriedades pozolânicas (FERREIRA et al., 2018). Os estudos selecionados analisaram a utilização do pó de vidro em substituição aos agregados naturais. Os blocos reciclados com vidro apresentaram resistências à compressão muito próximas e, até maiores que a dos blocos convencionais, bem como com porcentagens de absorção que atendem aos limites normativos. Ferreira et al. (2018) e Queiroz Jr. e Borja, (2016) obtiveram redução da resistência nos valores de 10 e $25 \%$ respectivamente, enquanto Silva (2019) obteve um acréscimo de 15\%. Apesar disso, em todos 
os estudos foram produzidos blocos que atenderam aos parâmetros normativos para a resistência à compressão.

Por sua vez, Benittez (2020) utilizou a escória de aciaria BSSF (baosteel's slag short flow) na produção dos blocos, resíduo gerado pela indústria siderúrgica proveniente do processo de beneficiamento do aço, constituído por ferro metálico, silicatos de cálcio, óxidos de magnésio e de cálcio, entre outros elementos químicos. Ensaio relativos às propriedades dos agregados atestaram que este resíduo apresenta massa específica inferior aos agregados naturais e menor absorção, sendo maior apenas que a absorção do pedrisco. A escória de aciaria foi incorporada aos agregados graúdos e miúdos em porcentagens de substituição de 20 a $80 \%$, sendo que, para todos os traços, foram obtidas resistências à compressão satisfatórias. Observou-se para os blocos com teores de substituição de 40 e $60 \%$, um acréscimo da resistência de 9,4 e $11,2 \%$, respectivamente, em relação aos blocos convencionais, enquanto para o bloco de $80 \%$, houve uma redução $28,3 \%$, devido ao prejuízo causado por elevados teores de incorporação do resíduo na coesão do bloco.

\subsection{Blocos de concreto com adição de resíduos orgânicos}

Segundo o Ministério do Meio Ambiente (2017), os resíduos orgânicos são aqueles constituídos por restos de animais ou vegetais que podem ter origem doméstica, urbana, agrícola, industrial ou de saneamento básico. A disposição inadequada e o grande volume gerado desse tipo de resíduo podem resultar em um grande problema ambiental.

De acordo com Mozer, Lopes e Woelffel (2019), a incorporação de serragem pode ser uma boa alternativa para produção de alvenaria de concreto com função não estrutural, devido ao material proporcionar conforto térmico, acústico e redução de peso para a construção, graças à sua baixa massa específica. Este resíduo se classifica de acordo com a norma técnica NBR-10004 (ABNT, 2004) como classe IIA, sendo um resíduo inerte que não apresente periculosidade.

Em seus estudos, Mozer, Lopes e Woelffel (2019) e Lima e Iwakiri (2014) incorporaram o resíduo de serragem da madeira Pinus spp. em substituição ao agregado miúdo na produção de blocos de concreto. No estudo de Mozer, Lopes e Woelffel (2019) realizou-se a incorporação do resíduo no teor de 5\%, enquanto Lima e Iwakiri (2014) produziram três traços com incorporação de $50 \%$ do resíduo de Pinus spp. no estado in natura, in natura com 4,5\% de $\mathrm{CaCl} 2.2 \mathrm{H} 2 \mathrm{O}$, e com pré-tratamento tipo extração em água fria por 48 horas e com 4,5\% de $\mathrm{CaCl} 2.2 \mathrm{H} 2 \mathrm{O}$. Devido à menor massa específica do pó de serragem, bem como seu elevado teor de absorção, o produto da fabricação dos blocos apresentou compósitos mais leves e mais absorventes em comparação com os blocos convencionais. Mozer, Lopes e Woelffel (2019) obtiveram redução da resistência a compressão para os blocos reciclados de $49 \%$, não atendendo aos parâmetros de resistência normativos. Os de Lima e Iwakiri (2014), mesmo com reduções entre 60,5 e 66,38\%, obtiveram resistências acima de $4 \mathrm{MPa}$, atendendo à norma.

Nas pesquisas realizadas por Almeida, Anacleto e Costa (2017) e Anacleto (2020), foram abordados o uso do resíduo de lodo proveniente de estações de tratamento de água. Esse resíduo orgânico é caracterizado por possuir elevado teor de umidade e absorção de água.

Almeida, Anacleto e Costa (2017) indicaram que o resíduo utilizado em seu estudo possuía uma massa de água cerca de seis vezes maior que a massa de sólidos, sendo indicada a utilização desse resíduo como agregado reciclado no estado seco, de forma a ser possível introduzir maior quantidade de rejeito. Os autores também apontam a necessidade de se analisar o teor de matéria orgânica incorporada no resíduo, devido ao seu potencial de ocasionar patologias no concreto e diminuir sua resistência. Nos estudos analisados foram incorporados o resíduo de lodo em substituição ao agregado miúdo em teores variando de 0,7 
a 3\%. Em ambas as pesquisas foi constatado um aumento na resistência a compressão dos blocos reciclados em comparação com os blocos de referência, apesar da menor massa específica e maior absorção do resíduo, fatores como a redução da relação água/cimento e uma seleção granulométrica adequada ao traço com resíduo resultaram no aumento da capacidade resistiva dos blocos reciclados.

Os blocos de Almeida, Anacleto e Costa (2017) apresentaram acréscimo de resistência entre 8,1 a $19,65 \%$ com o aumento do teor incorporado, e os de Anacleto (2020) um acréscimo de $11,09 \%$, bem como menor absorção de água. Todos os blocos apresentaram resistências acima de $6 \mathrm{MPa}$, sendo adequados para uso em alvenaria estrutural, de acordo com a norma.

Pesquisas também avaliaram a adição de fibras de celulose na mistura de concreto para os blocos. Prazeres (2018) produziu blocos com adição de fibras provenientes de folhas sulfite brancas no teor de $20 \%$ em relação ao volume de cimento. Apesar da alta capacidade de absorção da água das fibras de celulose, obtiveram-se blocos reciclados com resistência $7,4 \%$ maior que os blocos convencionais, devido à capacidade coesiva proporcionada pelas fibras. Alves (2016), por outro lado, obteve reduções na resistência com a adição dos teores de 0,5 e $1 \%$ das fibras de celulose provenientes do papel kraft, utilizado nas embalagens de cimento. Utilizando traços de referência com teores de argamassa nos valores de 61 e $91 \%$, obtiveram-se reduções da resistência de 65 e 5,6\%, respectivamente, em comparação com os blocos de referência, demonstrando a melhor inter-relação da fibra kraft com o traço de maior teor de argamassa. Em ambos os estudos, foi observado o aumento da absorção dos blocos com a adição das fibras, demonstrando que tantos as fibras provenientes de papel sulfite, quanto as de papel kraft, tornam o compósito mais absorvente. Apesar disso, os blocos produzidos por Alves (2016), com teor de argamassa de $91 \%$ e adição de fibra de $0,5 \%$, e os blocos de Prazeres (2018) obtiveram resistência para serem utilizados como vedação, de acordo com a norma.

Padilha (2017) trabalhou com o resíduo de casca de arroz, caracterizado por sua propriedade pozolânica, em substituição, nos teores de 5, 10 e $15 \%$, ao cimento, utilizando dois traços de concreto produzidos com os cimentos CPIV e CPI-ARI. Esse resíduo se mostrou eficiente na utilização como aglomerante, obtendo blocos com resistências que, apesar de menores que do bloco referência, ainda são adequadas para sua utilização como alvenaria de vedação ou estrutural.

Por sua vez, Terra (2018) produziu em seu estudo blocos com substituição de agregado miúdo por resíduo de quartzito em teores variados, com e sem a incorporação de $2,5 \%$ de fibra de coco em substituição ao pó de pedra. O quartzito agregou aos blocos um maior número de vazios com o aumento de sua incorporação, causando uma maior absorção e resistências à compressão menores que os blocos de referência. A adição das fibras de coco ao traço interferiu apenas na redução da absorção de água dos blocos, devido a possibilidade de ter servido na mistura como preenchimento dos poros. Verificou-se que apenas os blocos com incorporação de $25 \%$ apresentaram resistências satisfatórias, obtendo-se uma redução de $48,8 \%$ para o bloco com teor de $100 \%$.

Por fim, Caldas (2018) abordou em seu estudo a utilização de conchas de marisco como alternativa para o uso de agregados graúdos, substituindo a brita em teores de 10 a $100 \%$, observando uma leve redução na resistência com o aumento da incorporação do resíduo, obtendo maior redução na porcentagem de 19,3\% para o bloco com teor de $100 \%$. Apesar disso, todos os blocos em todos os teores apresentaram resistência suficiente para serem classificados como estruturais pela norma. 


\section{água/cimento \\ 3.5 Correlação entre resistência mecânica, absorção de água dos blocos e relação}

\subsubsection{Resistência mecânica e absorção de água}

Dentre os estudos citados nesta revisão bibliográfica foram coletados dados de resistência à compressão e absorção. Estes dados, quando disponíveis, foram tabulados a fim de analisar a influência no comportamento dos blocos de concreto, visto que alguns autores como Barreto et. al (2019), Araújo et al. (2019), Benittez (2020), dentre outros, apontaram para a relação inversamente proporcional entre a resistência à compressão e a absorção. Ao todo foram selecionados 188 dados, analisados por regressão linear, por meio de uma curva logarítmica, apresentada na Figura 1.

A curva logarítmica relacionando as variáveis de resistência à compressão e absorção da água resultou em um coeficiente de determinação de $0,1955\left(\mathrm{R}^{2}\right)$, indicando que $19,55 \%$ dos dados explicam o modelo determinado. Isso indica uma correlação moderada entre o aumento da resistência à compressão dos blocos com a redução das porcentagens de absorção. A partir disso, é possível inferir que embora essas duas propriedades possuam uma tendência em se comportar de modo inversamente proporcional entre si, elas não são completamente relacionadas. De acordo com Prado (2006) existem fatores que podem interferir na resistência à compressão e na porcentagem de absorção da água dos blocos, como por exemplo, os métodos de vibração e prensagem durante a confecção dos blocos e os materiais componentes do concreto.

Figura 1 - Correlação entre resistência mecânica e absorção da água

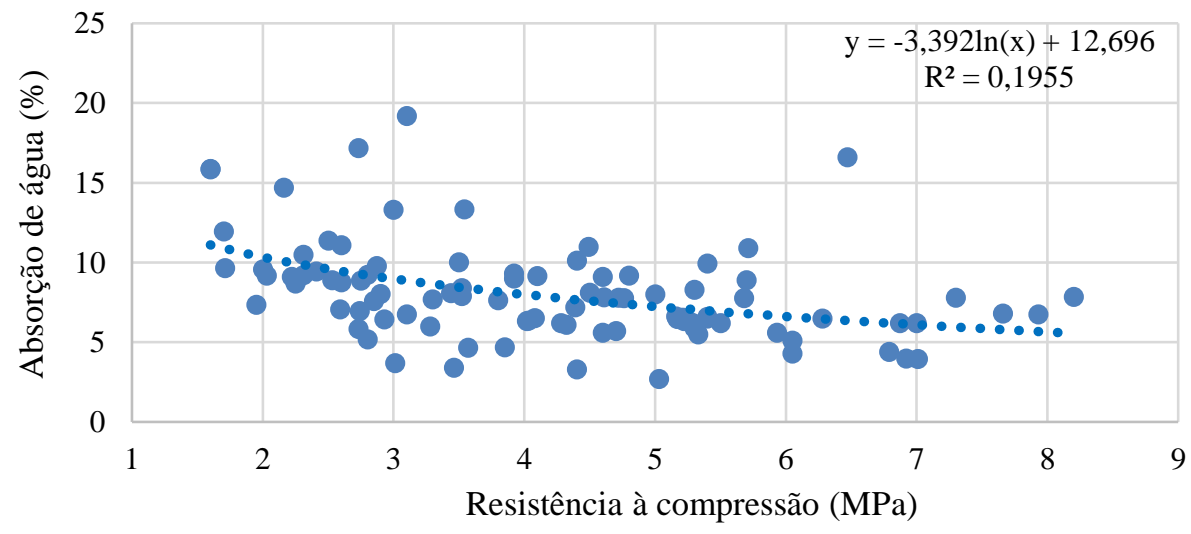

Por meio da Figura 2, nota-se a dispersão dos dados das variáveis de resistência à compressão e absorção de água para cada tipo de resíduo abordado nesta pesquisa. É possível observar que as menores dispersões entre as variáveis foram obtidas para os resíduos orgânicos $\left(\mathrm{R}^{2}=0,6492\right)$, seguido dos resíduos minerais, $\left(\mathrm{R}^{2}=0,2664\right)$ e dos resíduos de construção e demolição $\left(\mathrm{R}^{2}=0,1742\right)$, indicando que $64,92 \%, 26,64 \%$ e $17,42 \%$ dos dados explicam o modelo determinado, respectivamente. A menor correlação foi obtida para os dados referentes aos resíduos poliméricos, com baixo coeficiente de determinação $\left(\mathrm{R}^{2}=0,0493\right)$, indicando que apenas $4,93 \%$ dos dados explicam o modelo determinado, resultando em uma correlação bem fraca entre as variáveis.

É possível observar que as menores dispersões entre as variáveis foram obtidas para os resíduos orgânicos $\left(\mathrm{R}^{2}=0,6492\right)$, seguido dos resíduos minerais, $\left(\mathrm{R}^{2}=0,2664\right)$ e dos resíduos de construção e demolição $\left(\mathrm{R}^{2}=0,1742\right)$, indicando que $64,92 \%, 26,64 \%$ e $17,42 \%$ dos dados explicam o modelo determinado, respectivamente. A menor correlação foi obtida para os dados referentes aos resíduos poliméricos, com baixo coeficiente de determinação $\left(\mathrm{R}^{2}=0,0493\right)$, indicando que apenas $4,93 \%$ dos dados explicam o modelo determinado, resultando em uma correlação bem fraca entre as variáveis. 
Oliveira, Isabela; et al.; Blocos de concretos fabricados com incorporação de resíduos sólidos: Uma revisão sistemática. E\&S - Engineering and Science, 2020, 9:3.

Figura 2 - Correlação resistência mecânica e absorção de água para cada resíduo
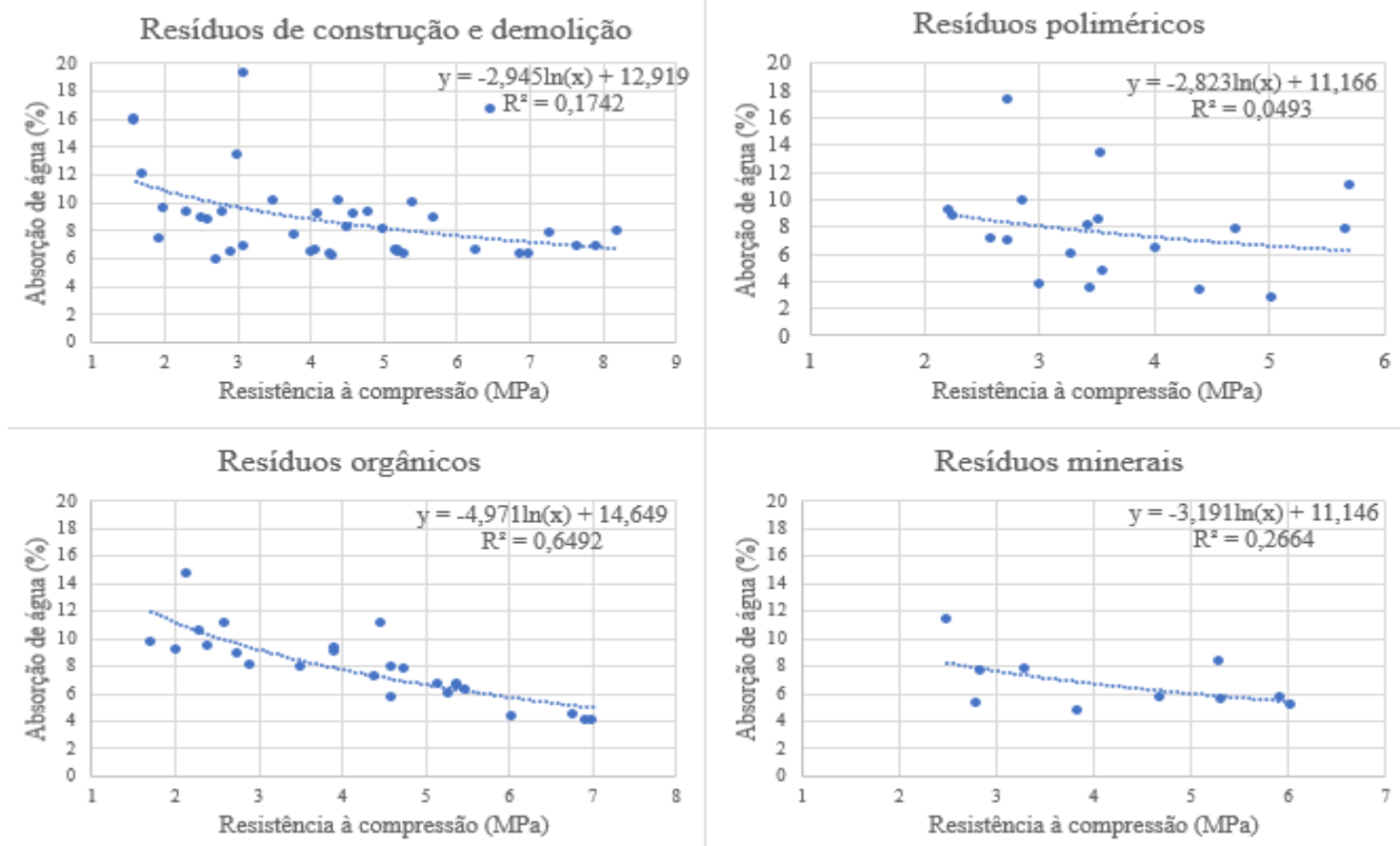

\subsubsection{Resistência mecânica e relação água/cimento}

Nos trabalhos selecionados também foram coletados e tabulados os dados de resistência à compressão e da relação água/cimento dos blocos de concreto, quando disponibilizados pelos autores. Ao todo, foram selecionados 110 dados, procedendo-se a análise de regressão, por meio de uma curva logarítmica, apresentada na Figura 3.

Figura 3 - Correlação entre resistência mecânica e relação água/cimento

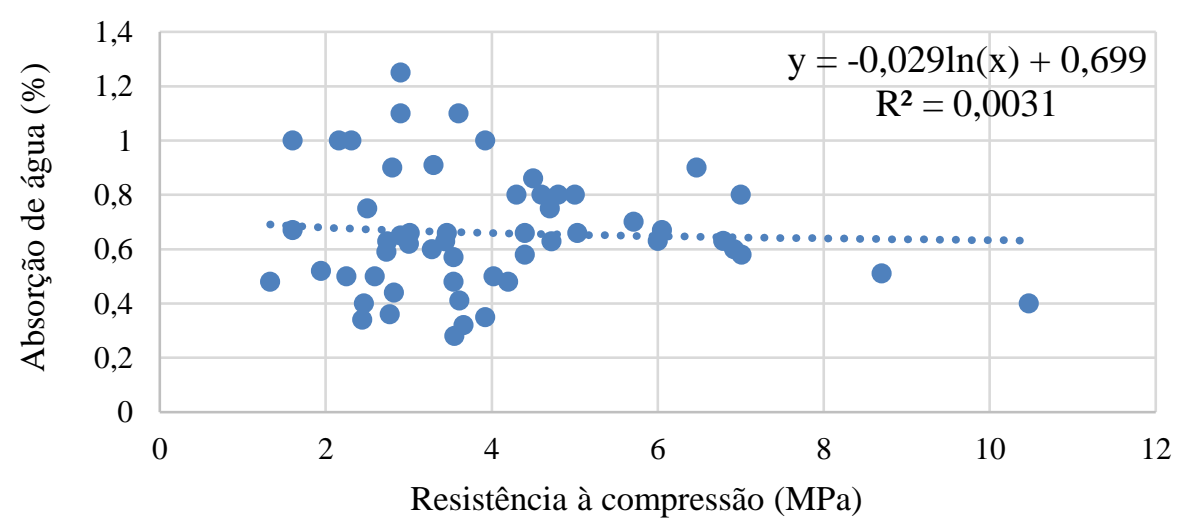

É possível observar que a correlação foi muito baixa, resultando em um coeficiente de determinação de 0,031 ( $\left.\mathrm{R}^{2}\right)$, indicando que apenas 3,1\% dos dados explicam o modelo determinado. Isso pode ter ocorrido devido ao fato de que, em muitos trabalhos, como os de Borges (2012), Mesquita et al. (2015), Gonçalves (2018), Mozer, Lopes e Woelffel (2019), entre outros, a água de amassamento foi adicionada à mistura de maneira empírica, por meio de tentativa e erro, adicionando-se água até ser obtida a consistência desejada para a mistura de concreto seco, o que pode variar dependendo do traço e do tipo de resíduo incorporado à mistura. Diante disso, e apesar de se notar uma queda na resistência com a elevação do fator água/cimento, não foi possível estabelecer uma adequada correlação entre estas variáveis. 
Estudos como o de Prado (2006) já haviam apontado a diferença no comportamento dos concretos secos e dos concretos plásticos em relação ao fator água/cimento. Prado (2006) afirmou que, diferentemente do concreto plástico, o concreto seco não obedece a Lei de Abrams, que estabelece uma relação direta entre a resistência à compressão e a relação água cimento, assim como não obedece a Lei de Lyse, que estabelece que a quantidade de água necessária para obter determinada trabalhabilidade depende do fator água/materiais secos e não do traço de concreto. De acordo com Frasson (2000) devido a água conferir maior plasticidade à mistura e facilitar a prensagem do material, para o concreto seco em geral quanto maior a quantidade de água adicionada à mistura maior será a resistência obtida. Prado (2006) afirma que deve ser adicionada aos blocos a maior quantidade de água possível, entretanto, esse aumento é limitado, pois valores elevados de umidade dificultam a desforma dos blocos.

\subsection{Agrupamento dos blocos quanto aos parâmetros físico-mecânicos}

Foi feita uma análise de agrupamento de forma a analisar melhor o comportamento dos dados de resistência à compressão e absorção de água dos blocos coletados neste estudo. O método aglomerativo adotado nesta análise foi o método de soma de erros quadráticos ou variância (Ward) e a distância métrica de Manhattan. O dendograma está representado na Figura 4.

Figura 4 - Agrupamento dos blocos a partir das propriedades de resistência à compressão e absorção de água

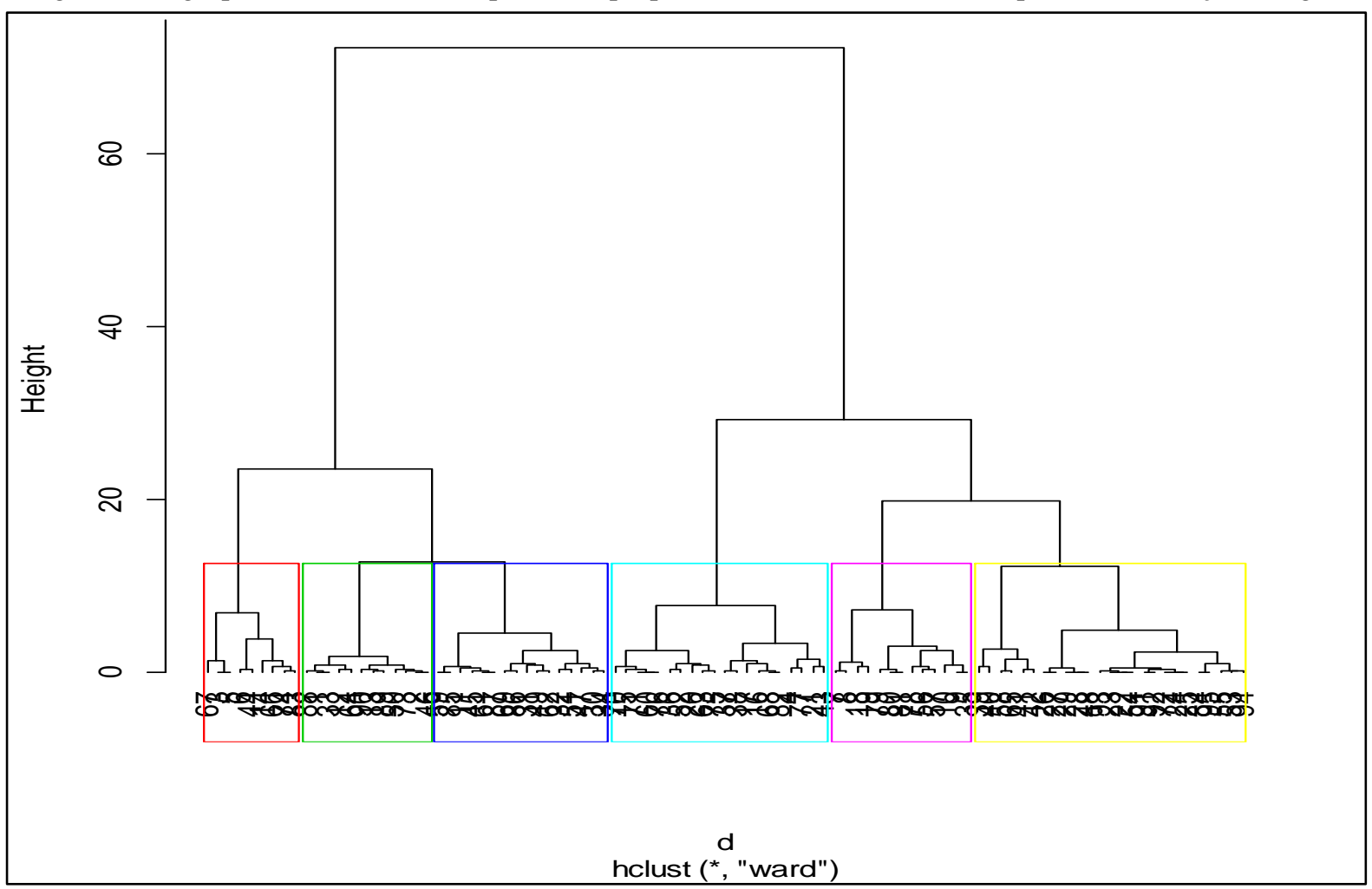

Fonte: Dendograma adaptado do programa Action.

Após a elaboração e análise de vários agrupamentos, concluiu-se que aquele com seis grupos é o que melhor representa o comportamento dos blocos pesquisados. É possível observar por meio do dendograma, a tendência desses grupos de se dividirem em dois ramos principais, que podem ser classificados pelas características dos blocos que compõem os agrupamentos. A partir disso, buscando-se analisar melhor o dendograma, classificou-se o ramo que agrupa os grupos 1, 2 e 3 como aquele que contém os blocos que, em geral, não 
apresentaram adequado comportamento quanto à resistência ou absorção, e o ramo que contém os grupos 4, 5 e 6, como aquele que contém os blocos que, em geral, obtiveram bom desempenho segundo a norma. Na Tabela 4 estão representados os valores médios obtidos nesses grupos para as propriedades de resistência à compressão e absorção de água.

Analisando individualmente cada grupo observou-se que, no grupo 1, encontram-se os blocos que apresentaram as maiores porcentagens de absorção de água, com a média de $13,11 \%$. Além disso, os blocos deste grupo apresentaram baixa resistência à compressão, com uma média de 2,33 MPa, abaixo do mínimo de $3 \mathrm{MPa}$ estabelecido pela norma. Com isso, observou-se que, nenhum bloco deste grupo atendeu simultaneamente aos requisitos de resistência e absorção da NBR 6136 (ABNT, 2016).

No grupo 2, também encontraram-se blocos com baixa resistência à compressão, com a média de 2,37 Mpa. Entretanto, todos os blocos que compuseram esse grupo, apesar de apresentarem absorção de água elevada, acima de 8,6\%, atenderam ao máximo de $10 \%$ estipulado pela norma. Apesar disso, devido à baixa resistência, nenhum bloco deste grupo atendeu, simultaneamente, aos limites normativos relativos à essas duas propriedades, assim como o grupo 1.

Já no grupo 3, foram agrupados blocos que apresentaram menores porcentagens de absorção de água em relação aos grupos 1 e 2, com uma média de 7,13\%. Em relação à resistência à compressão, este grupo obteve uma média de 3,03 $\mathrm{MPa}$, apresentando alguns blocos que obtiveram resistência satisfatória, acima de $3 \mathrm{MPa}$. Entretanto, a maioria deles não atendeu a este requisito e, devido a isso, obteve-se que, neste grupo, 53,33\% dos blocos não atenderam simultaneamente à ambas propriedades.

Por sua vez, o grupo 4 agrupou blocos que, em geral, obtiveram valores de resistências à compressão e absorção de água satisfatórios para a norma, com médias de 4,75 $\mathrm{MPa}$ e $8,84 \%$, respectivamente. Entretanto, apesar disso, alguns blocos deste grupo apresentaram absorção acima de $10 \%$ e, com isso, $20 \%$ dos blocos não atenderam simultaneamente aos requisitos de absorção e resistência.

Já o grupo 5 se destacou por agrupar os blocos com as maiores resistências à compressão, com uma média de 6,92 Mpa. Além disso, observou-se que, em relação a absorção de água, os blocos deste grupo obtiveram porcentagens bem menores que os blocos do grupo 4, apresentando uma média de 5,8\%. Devido a esses fatores, todos os blocos deste grupo atenderam simultaneamente aos parametros da norma em relação à essas propriedades.

Por fim, o grupo 6 também teve destaque por agrupar os blocos que obtiveram as menores porcentagen de absorção de água, com uma média de 5,6\%. Os blocos deste grupo também apresentaram resistências satisfatórias, na média de 4,67 MPa. Assim como no grupo 5, todos os blocos atenderam aos requisitos de resistencia e absorção da NRB 6136 (2016).

Tabela 4 - Valores médios de resistência à compressão e absorção por grupo

\begin{tabular}{l|c|c|c|c|c|c}
\hline Grupos & $\begin{array}{c}\mathbf{N}^{\mathbf{0}} \text { de } \\
\text { blocos }\end{array}$ & $\begin{array}{c}\text { Resistência à } \\
\text { compressão média } \\
(\mathbf{M P a})\end{array}$ & $\begin{array}{c}\text { Desvio padrão da } \\
\text { resistência à } \\
\text { compressão (MPa) }\end{array}$ & $\begin{array}{c}\text { Absorção de } \\
\text { água média } \\
(\boldsymbol{\%})\end{array}$ & $\begin{array}{c}\text { Desvio padrão } \\
\text { da absorção de } \\
\text { água (\%) }\end{array}$ & $\begin{array}{c}\text { Blocos que } \\
\text { atenderam a NBR } \\
\mathbf{6 1 3 6}(\mathbf{2 0 1 6}) \mathbf{( \% )}\end{array}$ \\
\hline Grupo 1 & 9 & 2,33 & 0,66 & 13,11 & 2,03 & $0 \%$ \\
\hline Grupo 2 & 12 & 2,37 & 0,36 & 9,2 & 0,36 & $0 \%$ \\
\hline Grupo 3 & 15 & 3,03 & 0,47 & 7,13 & 0,93 & $46,47 \%$ \\
\hline Grupo 4 & 20 & 4,75 & 0,65 & 8,84 & 1,14 & $80 \%$ \\
\hline Grupo 5 & 13 & 6,92 & 0,72 & 5,8 & 1,37 & $100 \%$ \\
\hline Grupo 6 & 25 & 4,67 & 0,72 & 5,6 & 1,17 & $100 \%$ \\
\hline
\end{tabular}


Apesar de não ter sido possível estabelecer uma relação entre os grupos e os tipos de resíduos incorporado nos blocos, devido aos resultados relacionados a esse fator serem inconclusivos, é possível observar que, de maneira geral, a maioria dos blocos analisados neste estudo, atendem aos requisitos da norma para resistência à compressão e absorção de água.

Além disso, por meio da análise do comportamento dos blocos perante as propriedades de absorção de água e resistência mecânica, foi possível observar a tendência dos blocos de obterem maiores resistência juntamente com menores porcentagens de absorção de água. Esse comportamento fica mais evidente ao se observar os grupos 1 e 5, que apresentaram a menor e a maior média de resistência à compressão, respectivamente, e obtiveram uma redução na absorção de água de aproximadamente 7,31\% para um aumento de resistência de 4,59 $\mathrm{MPa}$. Comportamento semelhante pode ser observado entre os grupos 2 e 6 , que obtiveram uma redução de 3,6\% na absorção de água para um aumento de 2,3 $\mathrm{MPa}$. Entretanto, não foi possível verificar este mesmo comportamento para os grupos 3 e 4 , que agruparam tanto blocos que atenderam quanto os que não atenderam a norma, visto que, apesar do grupo 4 ter obtido uma absorção média superior a do grupo 3, os blocos agrupados apresentaram uma resistência média 36,2\% maior. Este fator pode estar relacionado com os resultados obtidos através da análise de regressão feita anteriormente entre a resistência e a absorção de água, que indicou que apesar dessas duas propriedades apresentarem tendência em serem inversamente proporcionais, elas não são completamente relacionadas.

\section{ANÁLISE DOS BLOCOS QUE ATENDEM OS REQUISITOS NORMATIVOS}

Os 188 dados coletados nos estudos referentes à resistência à compressão e a absorção de água dos blocos de concreto reciclados foram analisados de acordo com a NBR 6136 (ABNT 2016), que estabelece uma resistência à compressão mínima para os blocos de concreto de alvenaria estrutural ou de vedação de $3 \mathrm{Mpa}$, bem como uma absorção média de água menor que 10\%, para agregados normais e, menor que 13\%, para agregados leves. Constatou-se que, dentre os blocos reciclados analisados que tiveram suas propriedades de resistência mecânica e absorção avaliadas nos estudos selecionados, aproximadamente $63,83 \%$ deles atenderam a ambos os parâmetros da norma, resultando em uma amostra de 94 blocos.

Analisando os blocos de acordo com o tipo do resíduo incorporado, constatou-se que, para uma amostra de 40 blocos com agregado de RCD, 60\% estiveram em conformidade com a norma, assim como, para uma amostra de 19 blocos com incorporação de resíduo polimérico, 68,42\% atenderam à norma e, para uma amostra de 10 blocos com resíduos minerais, essa porcentagem foi de $70 \%$. Já para os blocos produzidos com resíduos orgânicos, dos 25 blocos analisados, constatou-se que 64\% deles estiveram em conformidade com a norma. Apesar das correlações entre as resistências à compressão e as absorções de água dos blocos não serem altas, em geral os blocos reciclados apresentaram satisfatório desempenho, viabilizando seu uso como blocos estruturais ou de vedação.

Com vistas a difundir a incorporação dos resíduos para a produção de blocos de concreto, bem como fomentar a sustentabilidade dentro da cadeia da construção civil, apresenta-se na Tabela 6, os traços com capacidade de atendimento dos requisitos físicos e mecânicos normativos (quando fornecidos nos trabalhos). 
Oliveira, Isabela; et al.; Blocos de concretos fabricados com incorporação de resíduos sólidos: Uma revisão sistemática. E\&S - Engineering and Science, 2020, 9:3.

Tabela 6 - Traços que atendem aos requisitos físicos e mecânicos normativos.

\begin{tabular}{|c|c|c|c|c|}
\hline Autor & $\begin{array}{c}\text { Resíduo } \\
\text { Incorporado } \\
\end{array}$ & $\begin{array}{c}\text { Material } \\
\text { substituído }\end{array}$ & $\begin{array}{c}\text { Teor } \\
\text { incorporado } \\
\end{array}$ & Traço \\
\hline \multirow{5}{*}{$\begin{array}{l}\text { LINTZ et al. } \\
\qquad(2012)\end{array}$} & \multirow{5}{*}{$\mathrm{RCD}$} & \multirow{5}{*}{$\begin{array}{l}\text { Agregado } \\
\text { natural }\end{array}$} & $0 \%$ & $\begin{array}{l}\text { Traço em massa: (cimento: areia fina, areia } \\
\text { média: cascalho: água)-(1:3,5: 3,0: 2,5: } 0,80)\end{array}$ \\
\hline & & & $20 \%$ & Substituição de $20 \%$ dos agregados naturais \\
\hline & & & $50 \%$ & Substituição de $50 \%$ dos agregados naturais \\
\hline & & & $80 \%$ & Substituição de $80 \%$ dos agregados naturais \\
\hline & & & $100 \%$ & Substituição de $100 \%$ dos agregados naturais \\
\hline \multirow{5}{*}{ SILVA (2019) } & \multirow{5}{*}{ PET } & \multirow{5}{*}{$\begin{array}{l}\text { Agregado } \\
\text { miúdo }\end{array}$} & $0 \%$ & $\begin{array}{l}\text { (Cimento: Agregado Miúdo: Agregado } \\
\text { Graúdo: Água)-(1: 1,66: 1,66: 0,66) }\end{array}$ \\
\hline & & & $2,5 \%$ & $\begin{array}{c}\text { (Cimento: PET: Agregado Miúdo: Agregado } \\
\text { Graúdo: Água) - (1:0,041: 1,620: 1,660: } \\
0,66) \\
\end{array}$ \\
\hline & & & $5,0 \%$ & 1: $0,082: 1,575: 1,660: 0,66$ \\
\hline & & & $7,5 \%$ & 1: $0,124: 1,533: 1,660: 0,66$ \\
\hline & & & $10,0 \%$ & 1: $0,166: 1,492: 1,660: 0,66$ \\
\hline \multirow{2}{*}{$\begin{array}{c}\text { MATTAR e } \\
\text { VIANA (2012) }\end{array}$} & \multirow{2}{*}{ Polímero } & \multirow{2}{*}{$\begin{array}{l}\text { Agregado } \\
\text { Graúdo }\end{array}$} & $0 \%$ & $\begin{array}{l}1 / 17 \text { de cimento, } 6 \% \text { de água, } 27 \% \text { de areia, } \\
53 \% \text { de pó de pedra, } 20 \% \text { de brita/pedrisco, } \\
0 \% \text { de plástico* }\end{array}$ \\
\hline & & & $5 \%$ & $\begin{array}{l}1 / 17 \text { de cimento, } 6 \% \text { de água, } 27 \% \text { de areia, } \\
53 \% \text { de pó de pedra, } 15 \% \text { de brita/pedrisco, } \\
5 \% \text { de plástico* }\end{array}$ \\
\hline \multirow{4}{*}{$\begin{array}{l}\text { GONÇALVES } \\
(2018)\end{array}$} & \multirow{4}{*}{ EPS } & \multirow{4}{*}{$\begin{array}{l}\text { Agregado } \\
\text { graúdo }\end{array}$} & $0 \%$ & $\begin{array}{l}\text { Traço em Massa: (Cimento: Areia: Brita: } \\
\text { EPS: A/C) - }(1: 3,43: 4,2: 0: 0,5)\end{array}$ \\
\hline & & & $5 \%$ & $(1: 3,43: 4: 0,04: 0,5)$ \\
\hline & & & $10 \%$ & $(1: 3,43: 3,77: 0,077: 0,5)$ \\
\hline & & & $15 \%$ & $(1: 3,43: 3,56: 0,12: 0,5)$ \\
\hline \multirow{3}{*}{$\begin{array}{l}\text { BRAVO } \\
(2014)\end{array}$} & \multirow{3}{*}{$\begin{array}{l}\text { Borracha de } \\
\text { pneu e } \\
\text { metacaulim }\end{array}$} & \multirow{3}{*}{$\begin{array}{l}\text { Agregado } \\
\text { miúdo e } \\
\text { cimento }\end{array}$} & $0 \%$ & $\begin{array}{l}\text { Traço em volume: (Cimento: Agregado } \\
\text { miúdo: Fibra de borracha: Agregado graúdo: } \\
\text { Água/Cimento) - (1: 4,95: 0,00: 0,68: 0,629) }\end{array}$ \\
\hline & & & $9,20 \%$ & $(1: 4,43: 0,50: 0,68: 0,629)$ \\
\hline & & & $18 \%$ & $(1: 3,94: 1,00: 0,68: 0,629$ \\
\hline \multirow{2}{*}{$\begin{array}{l}\text { MARTINI } \\
\quad(2017)\end{array}$} & \multirow{2}{*}{$\begin{array}{l}\text { Areia de } \\
\text { fundição }\end{array}$} & \multirow{2}{*}{$\begin{array}{l}\text { Agregado } \\
\text { miúdo }\end{array}$} & $0 \%$ & $\begin{array}{c}\text { Areia grossa }(35 \%) \text {, Pó de pedra }(32 \%) \text { e } \\
\text { Pedrisco }(33 \%)^{*}\end{array}$ \\
\hline & & & $15 \%$ & $\begin{array}{l}\text { Areia grossa }(20 \%) \text {, Pó de pedra (32\%), } \\
\text { Pedrisco }(33 \%) \text { e ADF }(15 \%) *\end{array}$ \\
\hline \multirow{5}{*}{$\begin{array}{l}\text { BENITTEZ } \\
\quad(2020)\end{array}$} & \multirow{5}{*}{$\begin{array}{l}\text { Escória de } \\
\text { aciaria }\end{array}$} & \multirow{5}{*}{$\begin{array}{l}\text { Agregado } \\
\text { Graúdo e } \\
\text { Miúdo }\end{array}$} & $0 \%$ & $\begin{array}{l}\text { Traço em Volume: (Cimento: Pedrisco: } \\
\text { Areia: Pó de Pedra: Escoria BSSF: a/c) - } \\
(1: 3,29: 2,38: 7,29: 0: 1,25)\end{array}$ \\
\hline & & & $20 \%$ & $(1: 2,65: 1,89: 5,83: 2,59: 1,25)$ \\
\hline & & & $40 \%$ & $(1: 1,94: 1,46: 4,37: 5,18: 1,25)$ \\
\hline & & & $60 \%$ & $(1: 1,3: 0,97: 2,92: 7,78: 1,25)$ \\
\hline & & & $80 \%$ & $(1: 0,65: 0,49: 1,46: 10,37: 1,25)$ \\
\hline \multirow{2}{*}{$\begin{array}{l}\text { QUEIROZ e } \\
\text { BORJA } \\
(2016)\end{array}$} & \multirow{2}{*}{ Vidro } & \multirow{2}{*}{$\begin{array}{l}\text { Agregado } \\
\text { miúdo }\end{array}$} & $0 \%$ & $\begin{array}{l}\text { Traço em massa: (Cimento: Areia: Brita: Pó } \\
\text { de Pedra: Água) - (1: 4: 1,25: 1,25: 0,75) }\end{array}$ \\
\hline & & & $15 \%$ & $\begin{array}{c}\text { (Cimento: Areia: Brita: Vidro: Água) - } \\
(1: 4: 1,25: 1,25: 0,75)\end{array}$ \\
\hline
\end{tabular}


Oliveira, Isabela; et al.; Blocos de concretos fabricados com incorporação de resíduos sólidos: Uma revisão sistemática. E\&S - Engineering and Science, 2020, 9:3.

Tabela 6 - Traços que atendem aos requisitos físicos e mecânicos normativos (Continuação)

\begin{tabular}{|c|c|c|c|c|}
\hline Autor & \begin{tabular}{|c|} 
Resíduo \\
Incorporado
\end{tabular} & $\begin{array}{c}\text { Material } \\
\text { substituído }\end{array}$ & $\begin{array}{c}\text { Teor } \\
\text { incorporado }\end{array}$ & Traço \\
\hline \multirow{4}{*}{$\begin{array}{l}\text { LIMA e } \\
\text { IWAKIRI } \\
\text { (2014) }\end{array}$} & \multirow{4}{*}{$\begin{array}{l}\text { Madeira } \\
\text { Pinus }\end{array}$} & \multirow{4}{*}{$\begin{array}{l}\text { Agregado } \\
\text { miúdo e } \\
\text { cimento }\end{array}$} & $0 \%$ & $\begin{array}{c}\text { Traço em massa: (Cimento: Areia: Brita) - } \\
(1: 4,878: 4,753)\end{array}$ \\
\hline & & & $\begin{array}{l}50 \% \text { Pinus spp. } \\
\text { in natura }\end{array}$ & $\begin{array}{c}\text { Substituição de } 50 \% \text { do agregado miúdo no } \\
\text { traço referência }\end{array}$ \\
\hline & & & $\begin{array}{c}\text { 50PNCC } 50 \% \\
\text { Pinus in natura }+ \\
4,5 \% \text { de } \\
\mathrm{CaCl} 2.2 \mathrm{H} 2 \mathrm{O}\end{array}$ & $\begin{array}{c}\text { Substituição de } 50 \% \text { do agregado miúdo no } \\
\text { traço referência }\end{array}$ \\
\hline & & & $\begin{array}{c}\text { 50PAFCC }=50 \% \\
\text { Pinus spp. com } \\
\text { pré-tratamento } \\
\text { em água fria }+ \\
4,5 \% \text { de } \\
\mathrm{CaCl} 2.2 \mathrm{H} 2 \mathrm{O}\end{array}$ & $\begin{array}{c}\text { Substituição de } 50 \% \text { do agregado miúdo no } \\
\text { traço referência }\end{array}$ \\
\hline \multirow[t]{2}{*}{$\begin{array}{l}\text { PADILHA } \\
\text { (2017) }\end{array}$} & \multirow[t]{2}{*}{$\begin{array}{c}\text { Cinza de } \\
\text { casca de arroz }\end{array}$} & \multirow[t]{2}{*}{ Aglomerante } & $0 \%$ & $\begin{array}{c}\text { Traço em massa: (Cimento CPV: CCA: Areia } \\
\text { média: Areia fina: Brita: Aditivo) - } \\
(1: 0: 5,2: 1,6: 1,2: 0,1)\end{array}$ \\
\hline & & & $5 \%$ & $(0,95: 0,05: 5,2: 1,6: 1,2: 0,1)$ \\
\hline \multirow{4}{*}{$\begin{array}{l}\text { ALMEIDA, } \\
\text { ANACLETO } \\
\text { e COSTA } \\
(2017)\end{array}$} & \multirow{4}{*}{ Lodo de ETA } & \multirow{4}{*}{$\begin{array}{l}\text { Agregado } \\
\text { Miúdo }\end{array}$} & $0 \%$ & $\begin{array}{l}\text { Traço em massa: (Cimento: Areia: Brita: } \\
\text { Água) - }(1: 5,5: 4,5: 0,7)\end{array}$ \\
\hline & & & $0,70 \%$ & Substituição de $0,7 \%$ do Agregado miúdo \\
\hline & & & $1,40 \%$ & Substituição de 1,4\% do Agregado miúdo \\
\hline & & & $2,10 \%$ & Substituição de $2,1 \%$ do Agregado miúdo \\
\hline \multirow{2}{*}{$\begin{array}{l}\text { PRAZERES } \\
\text { (2018) }\end{array}$} & \multirow{2}{*}{$\begin{array}{c}\text { Papel } \\
\text { Reciclado }\end{array}$} & \multirow{2}{*}{$\begin{array}{l}\text { Adição ao } \\
\text { traço }\end{array}$} & $0 \%$ & $\begin{array}{c}\text { Traço em massa: (Cimento: Areia: Pó de pedra: } \\
\text { Água) - (1: 2: } 3: 0,35)\end{array}$ \\
\hline & & & $20 \%$ & $\begin{array}{l}\text { Adição de } 20 \% \text { em relação ao volume total de } \\
\text { cimento }\end{array}$ \\
\hline \multirow[b]{2}{*}{$\begin{array}{l}\text { TERRA } \\
(2018)\end{array}$} & \multirow[b]{2}{*}{$\begin{array}{l}\text { Quartzito e } \\
\text { fibra de coco }\end{array}$} & \multirow{2}{*}{$\begin{array}{l}\text { Substituição } \\
\text { de agregado } \\
\text { miúdo por } \\
\text { quartzito e } \\
\text { adição de } \\
\text { fibra de coco } \\
\text { ao traço em } \\
\text { relação ao } \\
\text { volume de pó } \\
\text { de pedra. }\end{array}$} & $0 \%$ & $\begin{array}{l}\text { 8,2\% de cimento CPV-ARI, } 45,9 \% \text { de areia, } \\
45,9 \% \text { de pó de pedra e } 8,8 \% \text { de água* }\end{array}$ \\
\hline & & & $25 \%$ de quartzito & $\begin{array}{c}\text { Substituição de } 25 \% \text { do agregado miúdo no } \\
\text { traço referência.* }\end{array}$ \\
\hline
\end{tabular}

*Foram fornecidas as proporções dos materiais componentes dos traços em porcentagem.

\section{CONSIDERAÇÕES FINAIS}

Neste trabalho, realizou-se uma revisão sistemática acerca dos estudos que abordaram a incorporação de resíduos de diversas origens na fabricação de blocos de concreto, com o intuito de analisar como esses materiais interferem na resistência à compressão e absorção de água dos blocos

Os dados referentes à resistência à compressão, absorção de água dos blocos e o fator água/cimento adotado nos traços foram coletados (quando disponibilizados) e relacionados por meio de análise de regressão expressa em uma curva exponencial, que forneceu melhor ajuste dos dados. Ao se relacionar os dados de resistência à compressão e absorção de água dos blocos obteve-se uma correlação moderada entre essas variáveis, com um índice de determinação moderado de $0,1955\left(\mathrm{R}^{2}\right)$. Ao se analisar essa correlação a partir dos tipos de resíduos incorporados aos blocos, obteve-se o maior índice de determinação para os blocos 
com resíduos orgânicos $\left(\mathrm{R}^{2}=0,6492\right)$, seguido dos blocos com resíduos minerais $\left(\mathrm{R}^{2}=0,2664\right)$, dos blocos com $\mathrm{RCD}\left(\mathrm{R}^{2}=0,1742\right)$, com menor correlação sendo obtida para os blocos com resíduos poliméricos $\left(\mathrm{R}^{2}=0,1742\right)$. Já para as variáveis resistência à compressão e relação água/cimento dos blocos obteve-se um índice de determinação baixo de 0,031 ( $\left.\mathrm{R}^{2}\right)$, o que pode estar relacionado ao comportamento do concreto seco em relação ao fator água/cimento, visto que de acordo Prado (2006), este concreto não obedece a Lei de Abrams.

Em relação à análise de agrupamento, constatou-se que seis grupos distintos apresentaram comportamentos similares relacionados à resistência à compressão e a absorção de água. Observou-se uma tendência em alguns grupos de obter maiores absorções de água em blocos com menores resistências, podendo-se relacionar este comportamento com a correlação estabelecida nessa pesquisa para essas variáveis por meio de análise de regressão.

Ao se separar os blocos por tipo de resíduo incorporado, obteve-se que mais de $60 \%$ dos blocos analisados atenderam aos parâmetros da NBR 6136 (2016) quanto à resistência à compressão e absorção de água. Isso demonstra que, basicamente, todos os resíduos analisados apresentaram blocos com potencial de atender às propriedades normativas para produção de blocos reciclados. No entanto, para o sucesso da incorporação de resíduos nos traços recomenda-se realizar uma cuidadosa analise das propriedades e características dos resíduos a serem utilizados, bem como a maneira que eles podem afetar as propriedades mecânicas dos blocos, de forma a se obter não apenas blocos de concreto sustentáveis, mas também eficientes e seguros.

\section{REFERÊNCIAS}

ASSOCIAÇÃO BRASILEIRA DE NORMAS TÉCNICAS. NBR 6136: Blocos vazados de concreto para alvenaria simples - requisitos. Rio de Janeiro, 2016. 10p.

NBR 10004: Classificação dos resíduos sólidos. Rio de Janeiro, 2004. 71p.

ALVES, L. S. Influência da adição de fibras de celulose (papel kraft) nas características dos blocos de concreto não estrutural. 2016. 129 f. Dissertação (Mestrado) - Curso de Estruturas e Construção Civil, Universidade de Brasília, Brasília, 2016.

ALMEIDA, L. F. S.; ANACLETO, M. G.; COSTA, W. A. C. Estudo da viabilidade da utilização de lodo de ETA em blocos vazados de concreto por meio da avaliação de propriedades mecânicas e acústica. 2017. 91 f. TCC (Graduação) - Curso de Engenharia Civil, Universidade Tecnológica Federal do Paraná, Curitiba, 2017.

ANACLETO, M. G. Análise do desempenho mecânico e acústico de blocos vazados de concreto com adição de resíduos de estação de tratamento de água. 2020. $137 \mathrm{f}$. Dissertação (Mestrado) - Pós-Graduação em Engenharia Civil, Universidade Tecnológica Federal do Paraná, Curitiba, 2020.

ARAÚJO et al. Uso de RCD na produção de blocos estruturais de concreto. In: CONGRESSO BRASILEIRO DO CONCRETO, 61., 2019. Fortaleza. Anais ... Fortaleza: IBRACON, 2019.

BARRETO, J. M. L. et al. Análise das propriedades físicas e mecânicas de blocos de concreto prensados sem função estrutural com incorporação de PET reciclado. Matéria (Rio J.), v. 24, n.2, e12357, 2019. DOI 10.1590/s1517-707620190002.0672. 
BASTOS, I. A.; CRUZ, L. F. DA; WOELFFEL, A. B. Fabricação de blocos de concreto para vedação com o uso de agregados reciclados em canteiro de obras. Revista Científica Faesa, Vitória, v. 12, n. 1, p. 52-58, mar. 2016. DOI: 10.5008/1809.7367.101

BENITTEZ, L. H. Utilização de escória de aciaria na fabricação de blocos de concreto. 2020. 103 f. Dissertação (Mestrado) - Pós-Graduação em Engenharia Civil, Universidade Federal de São Carlos, São Carlos, 2020.

BORGES, G. F. Produção de blocos de concreto para vedação: Análise da viabilidade técnico-econômica da utilização de agregados reciclados. 2012. 83 f. TCC (Graduação) Curso de Engenharia Civil, Universidade Federal do Rio Grande do Sul, Porto Alegre, 2012.

BRASIL. Lei $n^{\circ}$ 12.305, de 2 de AGOSTO de 2010. Institui a Política Nacional de Resíduos Sólidos; altera a Lei no 9.605, de 12 de fevereiro de 1998; e dá outras providências. Disponível em: http://www.planalto.gov.br/ccivil_03/_ato2007-2010/2010/lei/112305.htm. Acesso em: 13 out. 2020.

BRAVO, R. S. Análise de blocos de concreto com resíduo de borracha de pneu e metacaulim. 2014. 62 f. Dissertação (Mestrado). Faculdade de Engenharia Civil, Universidade Estadual Paulista "Julio de Mesquita Filho", Ilha Solteira, 2014.

CALDAS, A. A. Uso de conchas de marisco na fabricação de blocos vazados de concreto simples para alvenaria. Revista Ibero-Americana de Ciências Ambientais, Recife, v. 9, n. 5, p. 248-257, set. 2018. DOI 10.6008/CBPC2179-6858.2018.005.0022.

CALLEJAS, I. J. A. Caracterização do perfil de inovação do segmento de serviços por meio de análise de agrupamento. Cadernos de inovação em pequenos negócios. v. 3. n. 3, p. 68 80, nov. 2015.

CAMPOS, M. A. et al. Blocos de concreto com areia de descarte de fundição: Um case de sucesso de viabilidade econômica, propriedades mecânicas e de durabilidade. In: CONGRESSO ABIFA DE FUNDIÇÃO, 18., 2019, Campinas. Anais ... Campinas: ABIFA, 2019. Disponível em: https://www.abifa.org.br/conaf/trabalhos/. Acesso em: 12 out. 2020.

COSTA, J. A. Estudos de blocos de vedação com substituição parcial do agregado miúdo por borracha de pneu. 2020. 67 f. Dissertação (Mestrado) - Pós-graduação em Ciência e Tecnologia dos Materiais, Universidade Estadual Paulista "Júlio de Mesquita Filho", Presidente Prudente, 2020.

COSTA, P. G. S. Análise das viabilidades técnica, econômica e sustentável do bloco de concreto convencional em comparação com o bloco de concreto reciclável. 2017. 89 f. TCC (Graduação) - Curso de Engenharia Civil, Centro Universitário de Formiga, Formiga, 2017

DANIEL, W.; PIVA, J.; ANTUNES, E. Análise das características físicas e propriedades mecânicas de blocos de concreto com uso de resíduos de construção e demolição (RCD). 2018. 18 f. TCC (Graduação) - Curso de Engenharia Civil Revista, Universidade do Extremo Sul Catarinense, Criciúma, 2018. 
DONI, M. V. Análise de cluster: métodos hierárquicos e de particionamento. 2004. $92 \mathrm{f}$. TCC (Graduação) - Faculdade de Computação e Informática, Universidade Presbiteriana Mackenzie, Brasil, 2004.

DRESCH, A.; LACERDA, D. P.; ANTUNES JÚNIOR, J. A. V. Design Science Research: Método de Pesquisa para Avanço da Ciência e Tecnologia. Porto Alegre: Bookman, 2014. $204 p$

FERREIRA, A. P. et al. Estudo Experimental da Resistência de Blocos de Concreto com Vidro Moído como Agregado Miúdo. In: CONGRESSO BRASILEIRO DE PONTES E ESTRUTURAS, 10., 2018, Rio de Janeiro. Anais... Rio de Janeiro: ABECE, 2018. Disponível em: http://www.abpe.org.br/trabalhos2018/209.pdf. Acesso em: 12 out. 2020

SALVADOR FILHO, J. A. A. Blocos de concreto para alvenaria em construções industrializadas. 2007. Tese (Doutorado). 246 f. Escola de Engenharia de São Carlos, Universidade de São Paulo, São Carlos, 2007.

FRASSON JUNIOR, A. Proposta de metodologia de dosagem e controle do processo produtivo de blocos de concreto para alvenaria estrutural. 2020. 145 f. Dissertação (mestrado) - Pós-Graduação em Engenharia Civil, Universidade Federal de Santa Catarina, Florianópolis, 2000.

GHISLENI, G., LIMA, G. T. S. Estudo da viabilidade de reutilização da areia de fundição na produção de blocos de concreto e concreto convencional. Revista Gestão e Sustentabilidade Ambiental, Florianópolis, v. 9, n. esp., p. 551-570, mai. 2020. DOI: 10.19177/rgsa.v9e02020551-570.

GOMES; P. C. C. et al. Obtenção de blocos de concreto com utilização de resíduos reciclados da própria fabricação dos blocos. Ambiente Construído, Porto Alegre, v. 17, n. 3, p. 267 280, jul./set. 2017. DOI 10.1590/s1678-86212017000300175.

GONÇALVES, P. J. S. Emprego de EPS reciclado em blocos vazados de concreto para otimização do conforto térmico das edificações. 2018. 147 f. Dissertação (Mestrado) - PósGraduação em Engenharia Civil, Universidade Federal do Amazonas, Manaus, 2018.

QUEIROZ JR, C. C. ; BORJA, E. V. Análise da exequibilidade técnica de blocos de concreto vazado com resíduos de vidro como agregado artificial. In: CONGRESSO BRASILEIRO DE CERÂMICA, 60., p 1106-1117, 2016, Águas de Lindóia. Anais ... Águas de Lindóia: ABCERAM, 2016.

KOBAYASHI, V. Y. F. Análise da resistência à compressão de blocos estruturais de concreto simples com a utilização de resíduos de construção e demolição como agregado. 2018. 13 f. TCC (Graduação) - Curso de Engenharia Civil, Faculdade de Engenharia, Universidade Federal da Grande Dourados, Dourados, MS, 2018.

LIMA, A. J. M. DE; IWAKIRI, S. Utilização de resíduos da madeira de Pinus spp. como substituição ao agregado miúdo na produção de blocos de concreto para alvenaria estrutural. Ciência Florestal, Santa Maria, v. 24, n. 1, p. 223-235, mar. 2014. DOI $10.5902 / 1980509813339$. 
LINTZ, R. C. C. et al. Estudo do Reaproveitamento De resíduos de Construção Empregados na Fabricação de Blocos. Revista IBRACON de Estruturas e Materiais, São Paulo, v. 5, n. 2, 166-181 p. abr. 2012. Disponível em: https://www.scielo.br/scielo.php?pid=S1983$41952012000200004 \&$ script=sci_abstract\&tlng=pt. Acesso em: 13 out. 2020.

LOPES, I. R. M. B. Estudo dos resíduos de construção e demolição e suas aplicações na produção de blocos de concreto. 2017. 94 f. Dissertação (Mestrado) - Pós-Graduação em Sociedade Tecnologia e Meio Ambiente, UniEvangélica, Anápolis, 2017.

MACHADO, J. F. Reutilização de resíduos de construção e demolição para a fabricação de blocos de alvenaria. Revista Engenharia em Ação UniToledo, Araçatuba, v. 04, n. 01, p. 47 61, jan/jun. 2019. Disponível em: http://www.ojs.toledo.br/index.php/engenharias/article/view/3237. Acesso em: 13 out. 2020

MARTINI, N. C. Reuso de areia descartada de fundição para a confecção de blocos de concreto estrutural. 2017. 72 f. TCC (Graduação) - Curso de Engenharia Ambiental, Universidade Tecnológica Federal do Paraná, 2017.

MATTAR, D. C.; VIANA, E. Utilização de resíduos poliméricos da indústria de reciclagem de plástico em blocos de concreto. Revista Eletrônica em Gestão, Educação e Tecnologia Ambiental, Santa Maria, v. 8, n. 8, p. 1722- 1733, 2012. ISSN 2236-1170. DOI $10.5902 / 223611706471$

MESQUITA, L. C. et al. Análise da viabilidade técnica de utilização de resíduos de construção e demolição na fabricação de blocos de vedação. Reec - Revista Eletrônica de Engenharia Civil, [s.1.], v. 10, n. 3, p.30-40, 10 nov. 2015. DOI 10.5216/reec.v10i3.32651

MINISTÉRIO DO MEIO AMBIENTE. Gestão de Resíduos Orgânicos. Disponível em: https://www.mma.gov.br/cidades-sustentaveis/residuos-solidos/gest\%C3\%A3o-deres\%C3\%ADduos-org\%C3\%A2nicos.html. Acesso em: 12 out. 2020.

MOREIRA, L. S. et al. Reutilização de RCC e EPS na fabricação de blocos de concreto estrutural. Revista Infinity, Itapiranga, v. 2, n. 1, p. 36-54, 2017. Disponível em: http://revistas.faifaculdades.edu.br/index.php/infinity/article/view/296. Acesso em: 13 out. 2020.

MOZER, G. Z.; LOPES, A. U.; WOELFFEL, A. B. Confecção de bloco de concreto para vedação com substituição parcial do agregado miúdo por serragem. Revista Científica Faesa, [S.1], v. 15, n. 2, p. 29-51, jul. 2019. ISSN 2316-7327. Disponível em: http://revista.faesa.br/revista/index.php/Faesa/article/view/261. Acesso em: 13 out. 2020.

NEPOMUCEMO, L. C. S., REIS, M. A. B. B., COSTA, J. S. Bloco de concreto para vedação com resíduo de borracha de pneu e resíduo da construção civil (RCC) para alvenaria de vedação. In: ENCONTRO EM ENGENHARIA DA EDIFICAÇÕES E AMBIENTAL, 5., 2017, Cuiabá. Anais ... Cuiabá: UFMT, 2017. Disponível em: https://eventosacademicos.ufmt.br/index.php/eeea/eeea2017/paper/viewFile/5836/801.

Acesso em: 12 out. 2020.

NOVAES, B. G.; FUJIMOTO, A.; PETITTO, R. M. Blocos de Alvenaria Feitos de Concreto com Substituição Parcial de Areia por Resíduo da Construção Civil. In: Brazilian 
Technology Symposium, 2017, Campinas. Anais... Campinas: UNICAMP, p. 4, 2017. Disponível em: http://lcv.fee.unicamp.br/images/BTSym-17/Papers/77002.pdf. Acesso em: 13 out. 2020.

OLIVEIRA, A. L. Contribuição para a dosagem e produção de peças de concreto para pavimentação. 2004. 271 f. Tese (Doutorado) - Pós-Graduação em Engenharia Civl, Universidade Federal de Santa Catarina, Florianópolis, 2004.

OLIVEIRA, N. B. V., PEREIRA, P. H. S., NOGUEIRA, J. F. Avaliação das propriedades de blocos de concreto, com estudo comparativo de misturas adicionadas de borracha de pneus inservíveis e resíduos de Construção e demolição (RCD). In: SUSTAINABLE URBAN COMMUNITIES TOWARDS A NEARLY ZERO IMPACT BUILT ENVIRONMENT, 2016, Vitória. Anais ... Vitória: UFES, p. 323 -332, 2016.

PADILHA, S. A. Potencialidade do uso de cinza de casca de arroz em blocos de concreto de alvenaria estrutural: Segundo NBR 6136. 2017. 123 f. Dissertação (Mestrado) - PósGraduação em Arquitetura e Urbanismo, Universidade Federal de Pelotas, Pelotas, 2017.

PRADO, D. M. Propriedades físicas e mecânicas de blocos estruturais produzidos com agregados reciclados de concreto. 2006. 130 f . Dissertação (Mestrado) - Escola de Engenharia de São Carlos, Universidade de São Carlos. São Carlos, 2006

PRAZERES, M. S. Estudo comparativo entre blocos de concreto para Alvenaria de vedação comuns e blocos de concreto com adição de papel reciclado. 2018. $152 \mathrm{f}$. TCC (Gradução) - Curso de Engenharia Civil, Universidade Estadual do Maranhão, São Luís, 2018.

SILVA, A. F. et al. Caracterização físico-química e avaliação da viabilidade de reuso de "areias de fundição" para fabricação de blocos de concreto sem função estrutural. Revista Brasileira de Gestão e Engenharia, São Gotardo, n. 14, p. 83-104, jul. 2016. Disponível em: http://periodicos.cesg.edu.br/index.php/gestaoeengenharia/article/view/276. Acesso em: 13 out. 2020.

SILVA, G. R. et al. Avaliação do processo de fabricação de blocos de concreto leve com o uso do eps reciclado e garrafa pet. In: CONGRESSO TÉCNICO CIENTÍFICO DA ENGENHARIA E DA AGRONOMIA, 6., Palmas. Anais... Palmas: CONFEA, 2019. Disponível em: https://www.confea.org.br/index.php/eventos/contecc/contecc-2019/civil. Acesso em: 13 out. 2020.

SILVA, J. B. Avaliação do desempenho de blocos de concreto estrutural dosados com politereftalato de etileno (PET) micronizado. 2016. $135 \mathrm{f}$. Tese (Doutorado) - Programa de Doutorado em Engenharia de Processos, Universidade Federal de Campina Grande, Campina Grande, 2016.

SILVA, M. N. G. Reaproveitamento de resíduos de vidro temperado para produção de blocos de concreto tipo vedação. 2019. 22 f. TCC (Graduação) - Curso de Engenharia Civil, Centro Universitário de Goiás - Uni - Anhanguera, GOIÂNIA, 2019. 
TERRA, I. C. C. Blocos cimentícios produzidos com a incorporação de fibras de coco e resíduos de quartzito. 2018. 56 f. Dissertação (Mestrado) - Programa de Pós-Graduação em Engenharia de Biomateriais, Universidade Federal de Lavras, Lavras, 2018.

TIBURCIO, J. Utilização de areia reciclada de resíduo da construção civil e resíduos de garrafa pet para fabricação de blocos de concreto e argamassa. 2018. 99 f. TCC (Graduação) - Departamento de Engenharia Ambiental, Universidade Tecnológica Federal do Paraná, Londrina, 2018 